\title{
ANALYTICAL ASSESSMENT ON PROGRESSIVE COLLAPSE POTENTIAL OF NEW REINFORCED CONCRETE FRAMED STRUCTURE
}

\author{
Sumithra Chavan $\mathrm{S}^{1}$, A R Rajendra ${ }^{2}$ \\ ${ }^{l}$ P.G Student, Department of civil engineering Dayananda Sagar College, Bangalore, India \\ ${ }^{2}$ Dean of student's welfare \& Exams, Department of civil engineering Dayananda Sagar College, Bangalore, India
}

\begin{abstract}
Progressive collapse is a catastrophic partial or total failure that mostly occurs when a structure looses a primary structural component or more like a column or any vertical load resisting component due to natural or manmade hazard.

In this research paper a new undergoing construction of Reinforced concrete 12 storied building located in Whitefield, Bangalore is modelled in accordance with the actual drawings according to Indian standard codes and analysed for progressive collapse potential by using structural design and analysis software Etabs2013. For evaluating the effect of progressive collapse in accordance with the guidance of U.S General Service Administration (GSA) linear static method is followed.

The analytical model is checked for Demand capacity ratio by removing primary vertical support, one column at a time and evaluating whether the member is resistance to progressive collapse. Many such columns are removed and analysed to know the behaviour of building on abnormal loading conditions. The result shows that progressive collapse can be resisted by providing proper detailing and adequate reinforcement to the beams and columns.
\end{abstract}

Keywords: Progressive collapse, Demand Capacity Ratio (DCR), General Service Administration standards (GSA), Design software Etabs2013, linear static

\section{INTRODUCTION}

Progressive collapse is a chain reaction of failure that occurs when one or more vertical load carrying member is lost due to the accidental events. In recent years catastrophic events are increasing like world trade centre collapsed on September 11 2001, due to bombing attacks as a result 2,752 people died and also the collapse of twin towers caused extensive damage to the surrounding buildings, thereby in order to prevent or mitigate progressive collapse many research has been carried out by using different standard codes like GSA 2003, DOD 2005, UFC 2009, etc..

Unfortunately in conventional design only gravity load was considered to optimize the cost of the structure and to meet code requirements. In order to prevent progressive collapse a large number of studies have to be performed in minimizing the progressive collapse for major important buildings and potential for progressive collapse has to be evaluated for new and existing buildings by using modern tools.

\section{MODELLING FEATURES}

To understand the behavior of structure under typical column removal considerations, twelve storied Reinforced concrete framed structure having height of $36 \mathrm{~m}$ is considered. Storey height is $3 \mathrm{~m}$. The column cross section is $0.2 \times 1.3 \mathrm{~m}, 0.2 \times 1.05 \mathrm{~m}, 0.2 \times 0.75 \mathrm{~m} \& 0.2 \times 0.675 \mathrm{~m}$.
Beam size is $0.2 \mathrm{x} 0.4 \mathrm{~m}, 0.2 \mathrm{x} 0.55 \mathrm{~m}, 0.2 \mathrm{x} 0.75 \mathrm{~m} \& 0.3 \mathrm{x} 0.6 \mathrm{~m}$. The floor slabs are modeled as plates of $0.1 \mathrm{~m}, 0.125 \mathrm{~m}$, $0.15 \mathrm{~m}$ thickness. Walls having $230 \mathrm{~mm}$ thickness is considered on all the beams. All the supports are modeled as fixed supports. Linear static analysis is conducted on this model. Fig 1 shows typical floor plan.

To perform progressive collapse analysis by using linear static analysis two separate models has to be prepared as per IS 456-2000 in Etabs2013 software. One is for gravity loading and other model is for seismic loading as per IS1893-2002 load combinations by using the guidelines of GSA2003. 


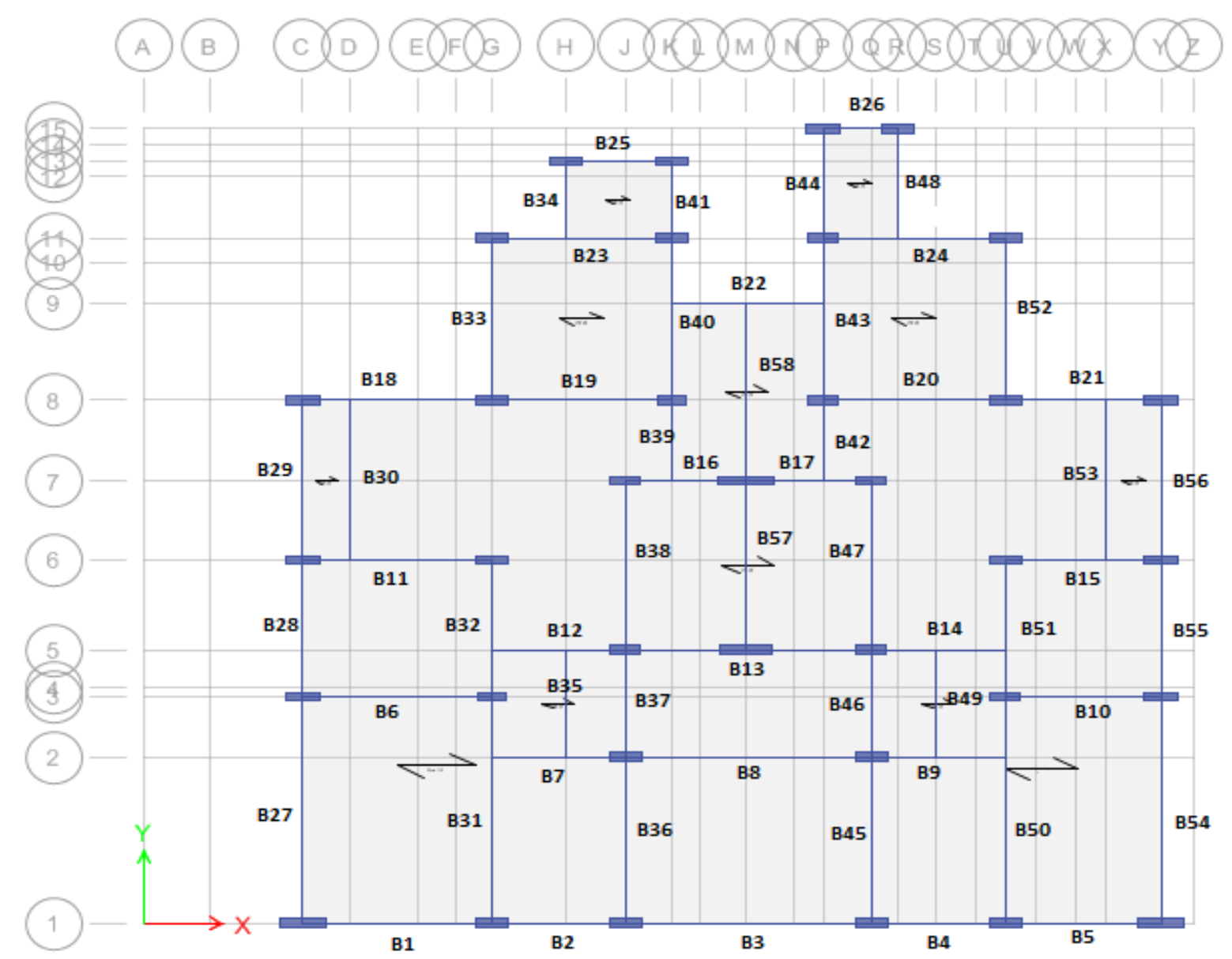

Fig1.Typical floor plan showing beam column layout

\section{ANALYSIS}

\subsection{Linear Static Analysis}

In the linear static analysis typical column is removed in the seismically designed model and analyzed to obtain demand at critical locations, from model with the gravity load imposed on the structure and running analysis capacity of the member is obtained, by dividing demand and capacity of the member DCR value in each structural member is calculated manually.

If the DCR of a member exceeds the acceptance criteria, the member is considered as failed. The demand capacity ratio calculated from linear static procedure helps to determine the potential for progressive collapse of building. 


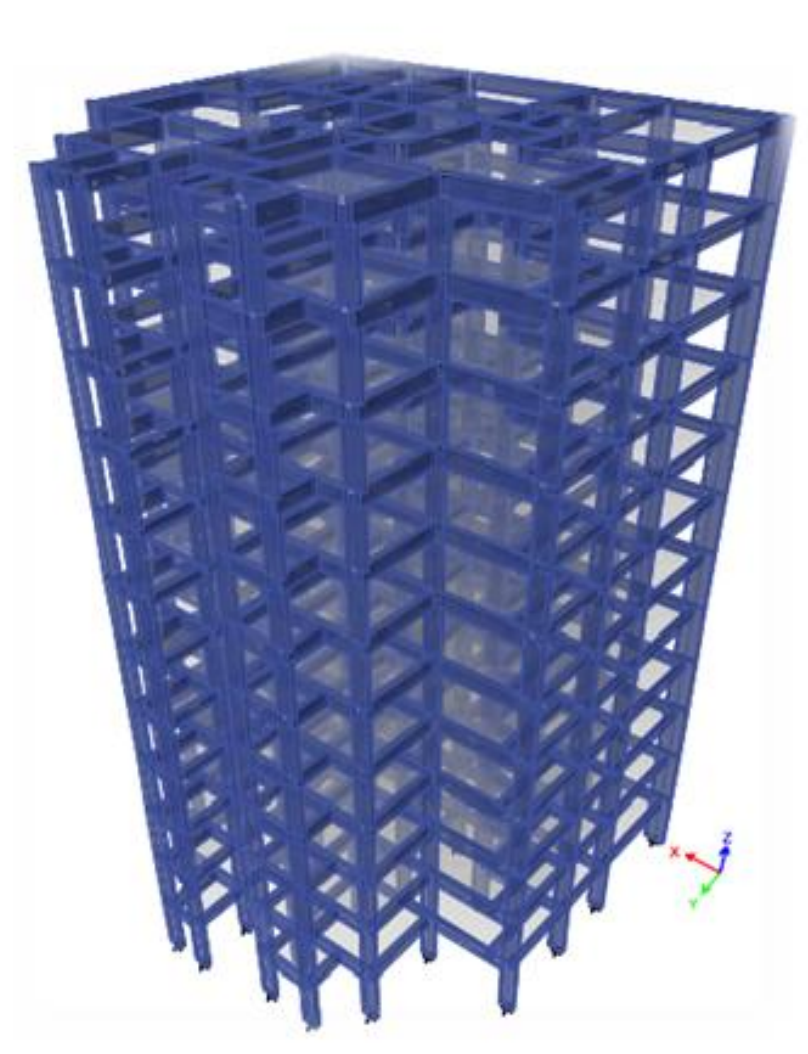

Design data is as follows:

Live Load: $3 \mathrm{kN} / \mathrm{m}^{2}$ on typical floor \& $1.5 \mathrm{kN} / \mathrm{m}^{2}$ on terrace

Floor Finish $: 1.5 \mathrm{kN} / \mathrm{m}^{2}$

\& Wall load on all beams: $13.8 \mathrm{kN} / \mathrm{m}$

+ Earthquake load: The Structure is designed for zone 2 as per IS18932002.

+ Type of soil: Type II (Medium)

+ Response reduction factor: 3

+ Importance Factor: 1

+ Characteristic Strength of Concrete $\left(F_{c k}\right): 25 \mathrm{~N} / \mathrm{mm}^{2} \& 45 \mathrm{~N} / \mathrm{mm}^{2}$

+ Yield Strength of reinforcing steel $\left(f_{\mathrm{N}}\right)$ : $500 \mathrm{~N} / \mathrm{mm}^{2}$

Fig2. 3D Model of 12 storied RC framed structure

\subsection{Loading}

According to GSA2003, for structure under investigation following load case should be defined which is 2(DL+0.25LL).

Where DL is Dead load and LL is live load.

\subsection{Acceptance Criteria}

Potential demand of both primary and secondary structural elements can be identified by performing linear static analysis for quantifying progressive collapse areas. The magnitude and distribution of these demands will be indicated by Demand-Capacity Ratios (DCR).

Acceptance criteria for the primary and secondary structural components shall be determined as:

$$
D C R=\frac{Q_{U D}}{Q_{C E}}
$$

Where,

QUD= Acting force (demand) determined in component or connection/joint moment, axial force, shear, and possible combined forces).
QCE $=$ Expected ultimate, un-factored capacity of the component and/or connection/joint (moment, axial force, shear and possible combined forces)

Structural elements and connections that have DCR values that exceed the following allowable values are considered to be severely damaged or collapsed. The allowable DCR values for primary and secondary structural elements should be less than or equal to 2 for typical structural configurations.

\subsection{Progressive Collapse Analysis}

The 12 storied reinforced concrete framed structures are designed as per IS456-2002 using ETABSV2013 software for dead, live and seismic loads. Then separate linear static analysis is performed for each case of column removal. Demand capacity ratio for flexure at all storeys' is calculated for four cases of column failure. To analyze corner column $\mathrm{C}$, column located at near the middle of the long side J1, column located at near the middle of the short side C6 \& interior column G3 is removed as per GSA. The specified IS 1893-2002 load combination is applied and the forces are calculated for all members using ETABS program.

The Demand Capacity Ratio (DCR), the ratio of the member force and the member strength is calculated. 


\section{RESULTS AND DISCUSSION}

The DCR values of the columns didn't exceed the acceptance criteria as per GSA But for the adjacent beams of the removed columns exceeds, they are represented graphically showing variation of DCR Vs Storeys is plotted. For column C1 removed adjacent beams B1 \& B27 exceeds acceptance criteria, aacordingly for other three cases of column removal.

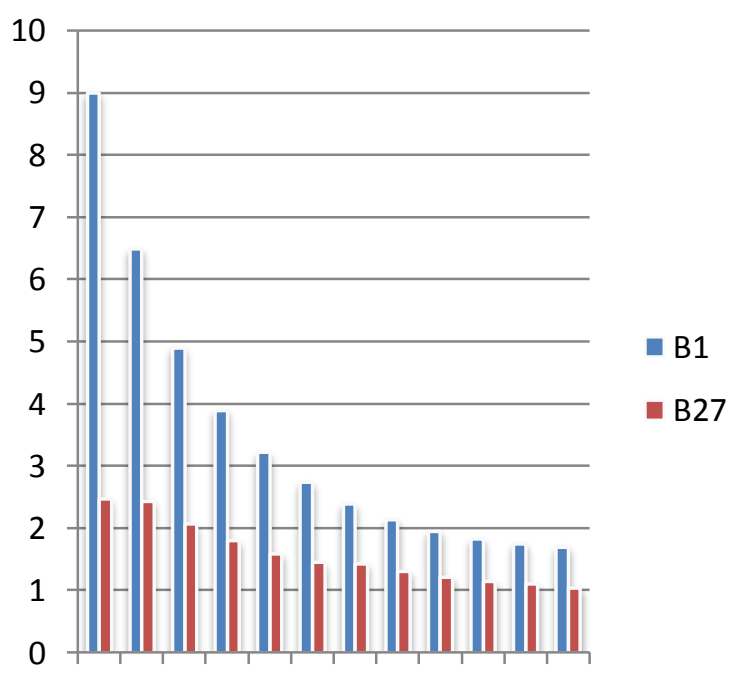

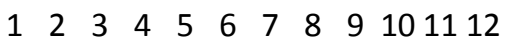

Fig3. C1 removed, B1 \& B27 exceeds acceptance criteria as per GSA for progressive collapse guidelines

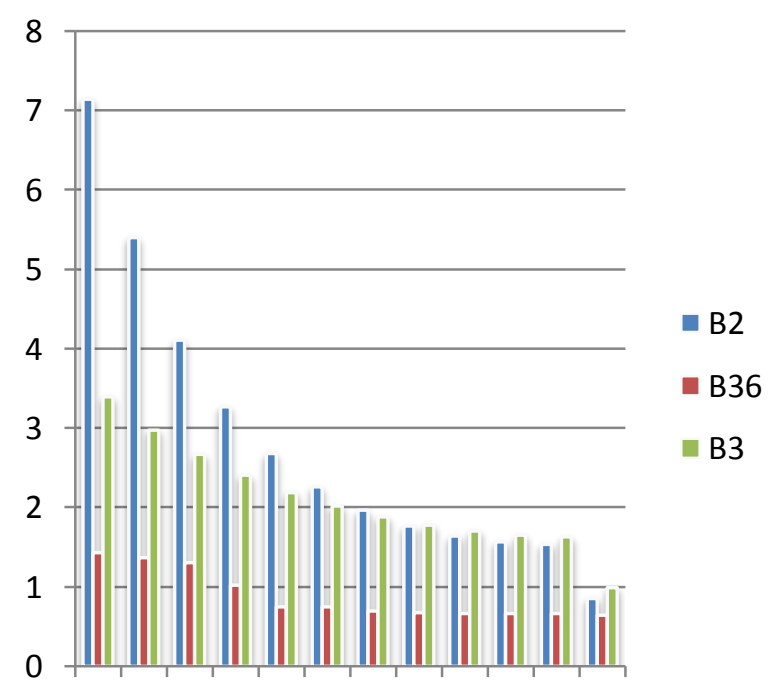

$\begin{array}{llllllllllll}1 & 2 & 3 & 4 & 5 & 6 & 7 & 8 & 9 & 10 & 11 & 12\end{array}$

Fig4. J1 removed, B2, B3 \& B36 exceeds acceptance criteria as per GSA for progressive collapse guidelines

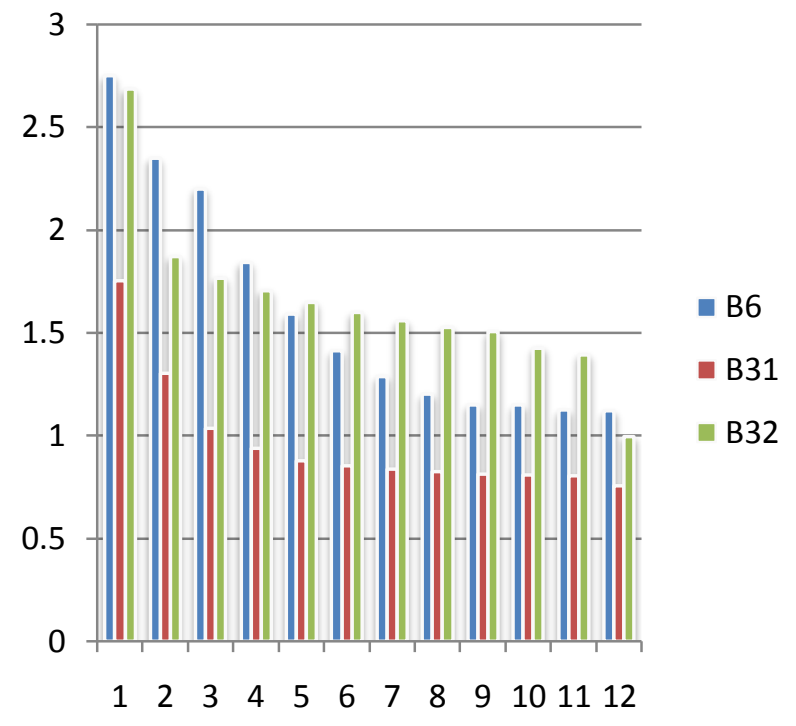

Fig5. G3 removed, B6, B31 \& B32 exceeds acceptance criteria as per GSA for progressive collapse guidelines

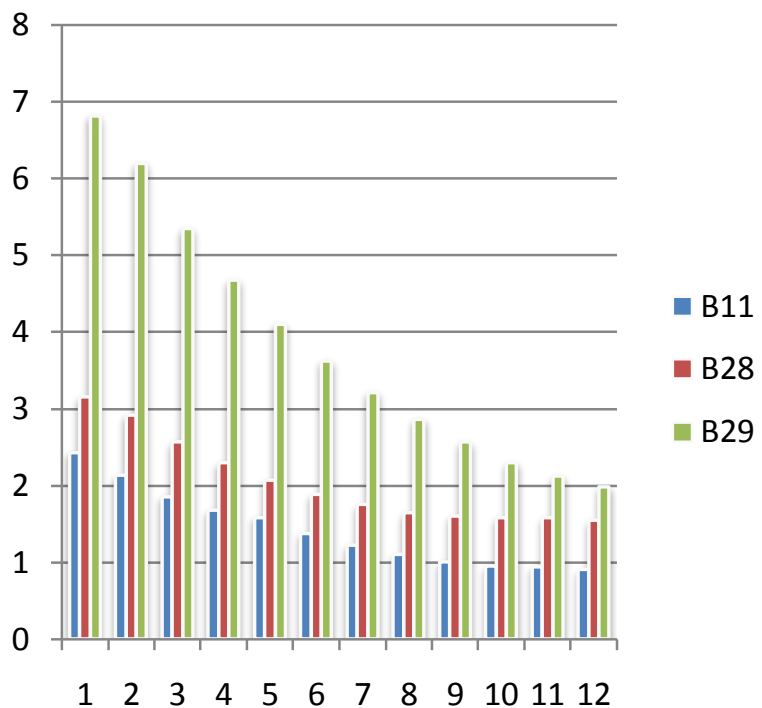

Fig6. C6 removed, B11, B28 \& B29 exceeds acceptance criteria as per GSA for progressive collapse guidelines

\section{CONCLUSION}

The removal of the column caused moment reversal in the intersecting beam so the beam exceeds acceptance criteria as shown in above graphs. In order to counter act the effect of reversal loading, proper detailing and adequate reinforcement should be provided to beams which are unsafe so it can develop alternative load paths and prevent progressive collapse.

\section{REFERENCES}

[1] Abhay A. Kulkarni, Rajendra R. Joshi- "Progressive Collapse Assessment of Structure". International Journal of Earth Sciences and Engineering ISSN 0974-5904, Volume 04, No 06 SPL, pp. 652-655, October 2011. 
[2] B.A. Izzuddin, A.G. Vlassis, A.Y. Elghazouli, D.A. Nethercot - Progressive collapse of multi-storey buildings due to sudden column loss Part I: Simplified assessment framework. Engineering Structures 30 (2008) 1308-1318.

[3] ETAB v 2013 analysis reference manual, Computers and Structures, Inc., Berkeley.

[4] Feng Fu- "Progressive collapse analysis of high-rise building with 3-D finite element modeling method". Journal of Constructional Steel Research 65, pp. 1269_1278, 2009.

[5] General Services Administration (GSA) (2003) Progressive collapse analysis and design guidelines for new federal office buildings and major modernization projects, GSA.

[6] IS 456:2000 (2005) Plain and reinforced concrete code of practice, 4th Revision, 7th Reprint, Bureau of Indian Standards, New Delhi.

[7] IS 1893 (Part 1):2002 (2006). Criteria for earthquake resistant design of structures.5th Revision, 3rd Reprint, Bureau of Indian Standards, New Delhi.

[8] Jun Li, Hong Hao 'Numerical study of structural progressive collapse using substructure technique' Engineering Structures, Volume 52, Pages 101-113, July 2013

[9] Jae-hyouk Choi, Dong-kuk Chang - 'Prevention of progressive collapse for building structures to member disappearance by accidental actions'. Journal of Loss Prevention in the Process Industries 22, pp.1016-1019, 2009

[10] Kapil Khandelwal, Sherif El-Tawil - 'Pushdown resistance as a measure of robustness in progressive collapse analyses. Engineering Structures 33, pp 2653-2661, 2011,

[11] Mehrdad Sasani, Andre Werner, Ali Kazemi - 'Bar fracture modelling in progressive collapse analysis of reinforced concrete structures'. Engineering Structures 33, pp. 401 409, 2009 ,

[12] STEVEN M. BALDRIDGE AND FRANCIS K. HUMAY, Preventing Progressive Collapse in Concrete Buildings, International Concrete ASCE. 